\title{
Response to antiretroviral therapy (ART): comparing women with previous use of zidovudine monotherapy (ZDVm) in pregnancy with ART naïve women
}

\author{
Susie Huntington ${ }^{1,2^{*}}$, Claire Thorne ${ }^{1}$, Jane Anderson ${ }^{3}$, Marie-Louise Newell $^{4}$, Graham P Taylor ${ }^{5}$, Deenan Pillay ${ }^{2,6}$, \\ Teresa Hill ${ }^{2}$, Pat Tookey ${ }^{1}$, Caroline Sabin ${ }^{2}$ and on behalf of the UK Collaborative HIV Cohort (UK CHIC) Study and \\ the National Study of HIV in Pregnancy and Childhood (NSHPC)
}

\begin{abstract}
Background: Short-term zidovudine monotherapy (ZDVm) remains an option for some pregnant HIV-positive women not requiring treatment for their own health but may affect treatment responses once antiretroviral therapy (ART) is subsequently started.

Methods: Data were obtained by linking two UK studies: the UK Collaborative HIV Cohort (UK CHIC) study and the National Study of HIV in Pregnancy and Childhood (NSHPC). Treatment responses were assessed for 2028 women initiating ART at least one year after HIV-diagnosis. Outcomes were compared using logistic regression, proportional hazards regression or linear regression.
\end{abstract}

Results: In adjusted analyses, ART-naïve $(n=1937)$ and ZDVm-experienced $(n=91)$ women had similar increases in CD4 count and a similar proportion achieving virological suppression; both groups had a low risk of AIDS.

Conclusions: In this setting, antenatal ZDVm exposure did not adversely impact on outcomes once ART was initiated for the woman's health.

Keywords: HIV, Pregnancy, Antiretroviral therapy, United Kingdom

\section{Background}

In the UK, zidovudine monotherapy (ZDVm) has been widely used for prevention of mother-to-child-transmission (PMTCT). Although combination antiretroviral therapy (ART) is now more commonly used for this purpose, ZDVm remains an option for pregnant women not on therapeutic ART with high CD4 counts $\left(>350\right.$ cells $\left./ \mathrm{mm}^{3}\right)$ [1], low viral loads $(<10,000$ copies $/ \mathrm{ml})$, and who are willing to deliver by elective caesarean section [2]. The 2012 BHIVA guidelines recommend that women opting to use ZDVm for PMTCT start ZDVm before 24 weeks

\footnotetext{
* Correspondence: susan.huntington.09@ucl.ac.uk

${ }^{1}$ Centre for Paediatric Epidemiology and Biostatistics, UCL Institute of Child Health, 30 Guilford Street, London WC1N 1EH, UK

${ }^{2}$ HIV Epidemiology and Biostatistics Group, UCL Research Department of Infection and Population Health, Royal Free Campus, Rowland Hill Street, London NW3 2PF, UK

Full list of author information is available at the end of the article
}

of pregnancy [2]. Pregnant women not on ART with $\mathrm{CD} 4 \leq 350$ cells $/ \mathrm{mm}^{3}$ are recommended to initiate longterm ART, as per the general UK HIV treatment guidelines [3].

Little is known about the impact of short-term ZDVm exposure on the woman's subsequent response to ART when started for her own health. In low- and middleincome settings use of single-dose nevirapine (sd-NVP) can have a negative impact on subsequent treatment responses to NVP-containing regimens, with high levels of drug resistance, particularly when ART is initiated within 6-12 months post-sd-NVP exposure [4,5]. However, whereas resistance to NVP requires a single mutation, resistance to ZDV requires multiple sequential mutations. As such, the development of resistance following shortterm ZDVm for PMTCT is uncommon [6-9] and limited to women with more advanced disease [10-13] who would 
not meet clinical criteria for ZDVm PMTCT use [2]. In contrast to the UK guidelines, ZDVm for PMTCT is no longer recommended within the updated consolidated World Health Organization (WHO) guidelines on use of ART; in line with the WHO guidelines' main focus on earlier initiation of ART to decrease transmission, pregnant women not yet on therapy are recommended to start longterm combination therapy regardless of CD4 count [14]. Despite these recent changes, there are many women in low- and middle-income settings with previous antenatal exposure to ZDVm who have yet to start ART for their own health [15]. In addition, use of ZDVm in pregnancy will remain a strategy for PMTCT in some settings until combination ART becomes more accessible.

Our aim was to test whether short-term exposure to ZDVm in a previous pregnancy has an adverse effect on treatment outcomes once a woman starts ART for her own health. Record linkage between the UK and Ireland National Study of HIV in Pregnancy and Childhood (NSHPC) and the UK Collaborative HIV Cohort (UK
CHIC) study gave us the opportunity to address this issue, which has implications for women with previous ZDVm experience.

\section{Methods}

We compared treatment outcomes among ART-naïve and ZDVm-experienced women starting therapeutic ART for their own health. Data were obtained from the UK CHIC study, an observational cohort that collates clinical data for adults receiving HIV-care at 15 large HIV clinics [16], and the NSHPC which collects antenatal data on all pregnant women diagnosed HIV-positive in the UK and Ireland [17]. Women reported to both studies were linked using demographic and clinical variables, as described elsewhere [18]. Data were not available on whether women had pregnancies prior to HIV diagnosis or infection, nor were data available on previous ART use outside the UK. Eligibility criteria were: initiating therapeutic ART at a UK CHIC site in 2000-2009 at least one year after HIV-diagnosis, either ZDVm-experienced or ART-naïve

Table 1 Characteristics of ART-naïve and ZDVm-experienced women when starting therapeutic ART in 2000-2009

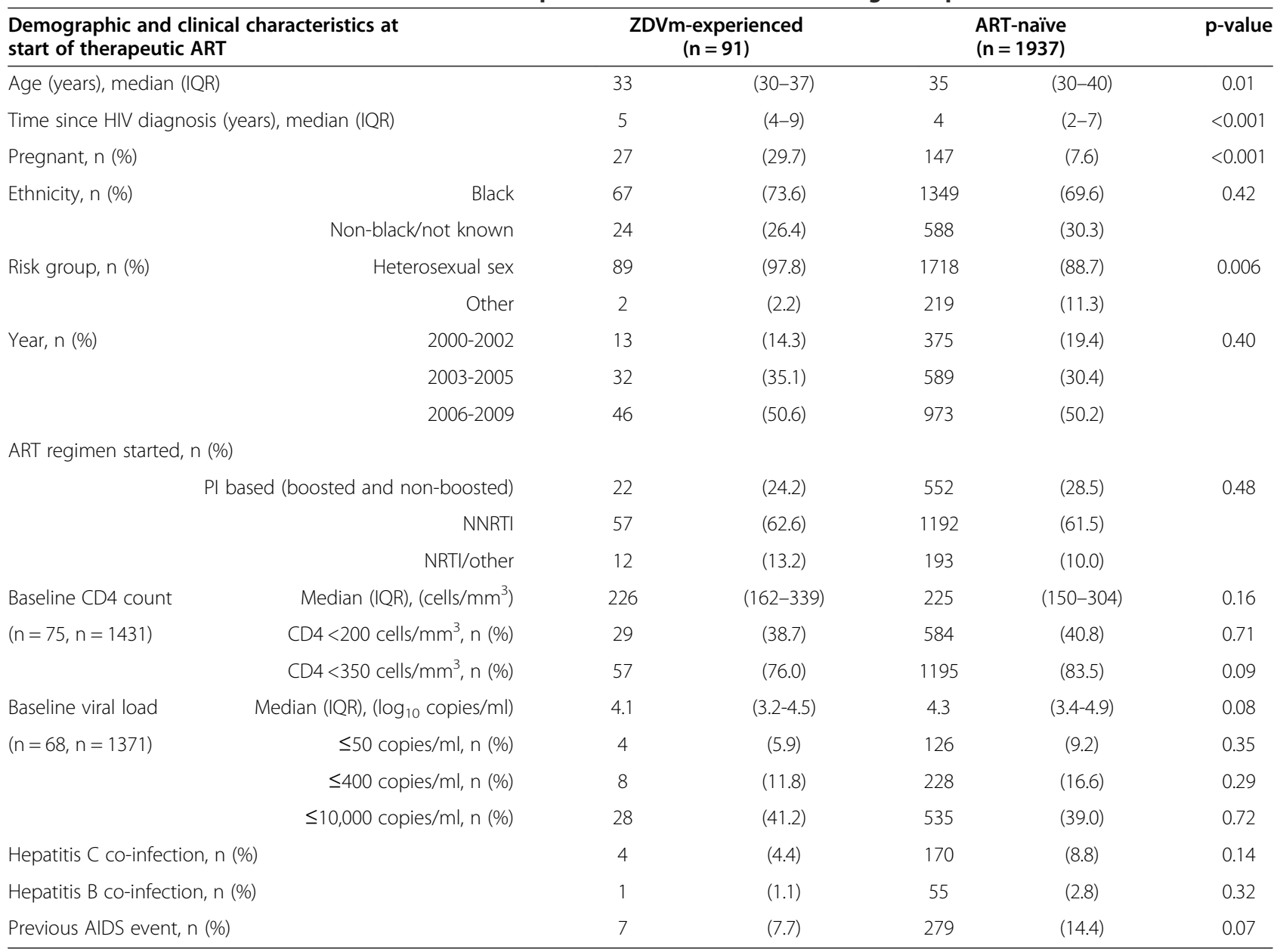

IQR, Interquartile range; PI, protease inhibitor; NNRTI, non-nucleoside reverse transcriptase inhibitor; NRTI, nucleoside reverse transcriptase inhibitor. 
(combination ART-experienced women were excluded), and aged $\leq 49$ years at HIV-diagnosis. Women were categorised as ZDVm-experienced if, according to NSHPC or UK CHIC data, they had ever used short-term ZDVm during pregnancy.

Baseline CD4 count and viral load were taken as the latest measurement within the three months before ART initiation. Characteristics of women starting treatment were compared using the Chi-square, Fisher's exact or Wilcoxon two-sample test. ART outcomes were compared using logistic regression, proportional hazards regression or linear regression.

The UK CHIC Study has multicentre ethics committee approval (MREC/00/7/47). Ethics approval for NSHPC was renewed following review by the London Multi-Centre Research Ethics Committee in 2004 (MREC/04/2/009).

\section{Results}

Overall, 1937 ART-naïve and 91 ZDVm-experienced women started therapeutic ART in 2000-2009. ZDVmexperienced women had used ZDVm in either one $(n=84)$ or two pregnancies $(n=7)$. No infants acquired HIV. ZDVm was used for a median of 12 weeks (IQR 8-16) and was typically started at 28 weeks gestation (range 17-39, IQR 24-31). The median duration between delivery (of the latest pregnancy) and starting therapy was 43 months (IQR 30-63); six women started within 12 months of delivery, none within 6 months.
In both groups some women were known to have had one or more previous pregnancies during which no ART was used (2.6\% (51/1937) ART-naïve women and 11.0\% (10/91) ZDV-experienced women). These pregnancies either ended early, due to termination or miscarriage, or resulted in a live birth where HIV was not diagnosed until delivery.

The baseline demographic and clinical characteristics of ZDVm-experienced and ART-naïve women at the time of starting therapeutic ART are summarised in Table 1. The median follow-up time was the same for both groups (4 [IQR 2-6] years, $\mathrm{p}=0.77$ ). Median time since HIVdiagnosis was 5 [4-9] years for ZDVm-experienced and 4 [2-7] years for ART-naïve women $(\mathrm{p}<0.001)$. ZDVmexperienced women were younger than ART-naïve women (33 [30-37] and 35 [30-40] years, respectively, $\mathrm{p}=0.01$ ), more likely to have been infected heterosexually (97.8\% vs. $88.7 \%, \mathrm{p}=0.006$ ) and more likely to start therapy during pregnancy $(29.7 \%$ vs. $7.6 \%, p=0.001)$. A similar proportion of women were of black ethnicity (black-African, blackCaribbean or black-other) (ZDVm-experienced: 73.6\%; ART-naïve: $69.6 \%, \mathrm{p}=0.42)$. Overall, 28.3\% ( $\mathrm{n}=574)$ used a PI-based regimen (ritonavir-boosted or non-boosted), $61.6 \%(\mathrm{n}=1249)$ an NNRTI-based regimen and $10.1 \%$ $(\mathrm{n}=205)$ an NRTI or other regimen. The regimens used were similar regardless of prior ZDVm experience $(\mathrm{p}=0.48)$. ZDVm-experienced women were more likely to have at least one viral load measurement recorded in the first year of treatment (ZDVm-experienced: 95.6\%;

Table 2 Treatment outcomes for ART-naïve and ZDVm-experienced women starting therapeutic ART in 2000-2009

\begin{tabular}{|c|c|c|c|c|c|c|c|}
\hline \multirow{2}{*}{$\begin{array}{l}\text { Variable } \\
\text { Death/AIDS event within } 1 \text { year, n (\%) }\end{array}$} & \multicolumn{2}{|c|}{$\begin{array}{l}\text { ZDVm-experienced } \\
\qquad \mathrm{N}=91\end{array}$} & \multicolumn{2}{|c|}{$\begin{array}{c}\text { ART-naïve } \\
N=1937\end{array}$} & \multirow{2}{*}{$\begin{array}{c}\begin{array}{c}\text { Unadjusted/ } \\
\text { Adjusted* }^{*}\end{array} \\
0.45\end{array}$} & \multirow{2}{*}{$\begin{array}{l}95 \% \mathrm{Cl} \\
0.16-1.19\end{array}$} & \multirow{2}{*}{$\begin{array}{c}\text { p-value } \\
0.11\end{array}$} \\
\hline & 1 & $(1.1)$ & 92 & $(4.8)$ & & & \\
\hline & & & & & 0.59 & $0.22-1.60$ & 0.30 \\
\hline \multirow[t]{2}{*}{ CD4 cell count change at 6 months, median cells $/ \mathrm{mm}^{3}(\mathrm{IQR})^{\mathrm{a}}$} & 106 & $(41-171)$ & 106 & $(34-197)$ & -0.66 & $-49.5-24.6$ & 0.51 \\
\hline & & & & & -0.68 & $-44.6-29.2$ & 0.68 \\
\hline \multirow[t]{2}{*}{ CD4 cell count change at 12 months, median cells $/ \mathrm{mm}^{3}(\mathrm{QQR})^{\mathrm{b}}$} & 153 & $(61-233)$ & 160 & $(70-256)$ & -1.2 & $-71.3-18.1$ & 0.24 \\
\hline & & & & & -0.83 & $-63.3-25.7$ & 0.41 \\
\hline \multirow[t]{2}{*}{ Virological suppression at 6 months, $n(\%)^{c}$} & 53 & $(74.7)$ & 1115 & $(74.4)$ & 1.01 & $0.59-1.75$ & 0.96 \\
\hline & & & & & 1.00 & $0.56-1.73$ & 0.97 \\
\hline \multirow[t]{2}{*}{ Virological suppression at 12 months, n (\%) ${ }^{d}$} & 52 & $(78.8)$ & 1108 & $(77.8)$ & 1.06 & $0.58-1.94$ & 0.85 \\
\hline & & & & & 1.06 & $0.57-1.96$ & 0.86 \\
\hline \multirow[t]{2}{*}{ Achieved virological suppression within 1 year, $\mathrm{n}(\%)^{\mathrm{e}}$} & 75 & $(86.2)$ & 1408 & $(84.7)$ & 1.30 & $1.03-1.64$ & 0.03 \\
\hline & & & & & 1.28 & $1.01-1.62$ & 0.04 \\
\hline \multirow{2}{*}{$\begin{array}{l}\text { Virological rebound among those achieving virological } \\
\text { suppression within } 6 \text { months, } n(\%)^{f}\end{array}$} & 16 & (22.9) & 197 & (16.6) & 1.54 & $0.93-2.57$ & 0.10 \\
\hline & & & & & 1.51 & $0.90-2.53$ & 0.12 \\
\hline \multicolumn{8}{|c|}{ 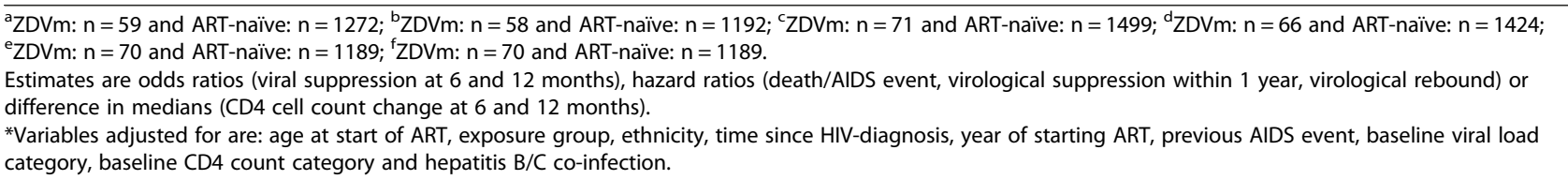 } \\
\hline
\end{tabular}


ART-naïve: 85.9\%, adjusted Odds Ratio 3.24 [95\% confidence interval 1.08-9.75], $\mathrm{p}=0.04$ ), however the median number of measurements recorded was the same (ZDVmexperienced: median 4 [IQR 3-5]; ART-naïve: median 4 [2-5], $\mathrm{p}=0.83)$.

ZDVm-experienced and ART-naïve women started therapeutic ART at similar baseline CD4 counts (ZDVmexperienced: 226 [162-339] cells $/ \mathrm{mm}^{3}$; ART-naïve: 225 [150-302] cells $/ \mathrm{mm}^{3}, \mathrm{p}=0.16$ ) and viral load (ZDVmexperienced: 4.1 [3.2-4.5] $\log 10$ copies/ml; ART-naïve: 4.3 [3.4-4.9] $\log 10$ copies $/ \mathrm{ml}, \mathrm{p}=0.08$ ). Few women in either group were known to have hepatitis B (ZDVmexperienced: $1.1 \%$; ART-naïve: $2.8 \%, \mathrm{p}=0.32$ ) or hepatitis $\mathrm{C}$ co-infection (ZDVm-experienced: $4.4 \%$; ART-naïve: $8.8 \%$, $\mathrm{p}=0.14)$. Few women had previously had an AIDS event (ZDVm-experienced: 7.7\%; ART-naïve: $14.4 \%, \mathrm{p}=0.07$ ).

ZDVm-experienced and ART-naïve women had similar treatment outcomes (risk of an AIDS event or death, CD4 cell count change) in the first year of therapy (Table 2). Where viral load data were available, most women had undetectable viral load at 12 months $(77.9 \%$, 1160/1490). ZDVm-experienced women were more likely to achieve virological suppression $(\leq 50$ copies $/ \mathrm{ml})$ within the first year of treatment (Table 2) and achieved virological suppression more quickly than ART-naïve women (median 2.5 [IQR 1.3-3.4] months versus 3.0 [1.7-4.8] months, respectively, hazard ratio (HR): 1.30 [95\% CI 1.03-1.64], $\mathrm{p}=0.03$, aHR: 1.28 [1.01-1.62], $\mathrm{p}=0.04)$.

\section{Discussion}

This UK study indicates that where ZDVm is used in pregnancy to prevent MTCT among women with high CD4 count and viral load $<10,000$ copies/ml it does not have a deleterious effect on treatment outcomes when ART is subsequently started. This adds support to the limited number of studies which indicate that shortterm use of ZDVm for PMTCT is not detrimental to women's long-term health $[7,9,19,20]$ and provides some reassurance with respect to the large number of women in lower-resourced settings with prior antenatal ZDVm exposure who have not yet initiated treatment. However, as a substantial proportion of these women may have had higher viral load in pregnancy $[21,22]$, their outcomes may be different. The increased likelihood of achieving viral suppression among ZDV-experienced women may be due to better treatment adherence or frequency of viral load monitoring. ZDVm-experienced women were more likely to have a viral load measure reported in the first year of treatment indicating that they had better contact with clinical care. If having a previous pregnancy, and shortterm use of ART in that pregnancy, results in better engagement in clinical care when a woman subsequently starts therapy for her own health, this could mask any deleterious effect of the previous ART exposure. No data were available on previous pregnancies before HIV diagnosis or ART use outside the UK, something that may impact treatment outcomes. Therefore, further investigation is required to assess the long-term impact of short-term antenatal ART used for PMTCT.

\section{Conclusions}

In this setting, antenatal ZDVm exposure did not adversely impact on outcomes once ART was initiated for the woman's health. This was a small study with limited statistical power and further research is required to support these findings.

\section{Competing interests}

The authors declare that they have no competing interests.

\section{Authors' contributions}

SH carried out the statistical analysis and drafted the manuscript. TH undertook data acquisition. All authors contributed to the interpretation of data and drafting of the manuscript. All authors read and approved the final manuscript.

\section{Acknowledgements}

UK CHIC: Steering Committee: Jonathan Ainsworth, Jane Anderson, Abdel Babiker, David Chadwick, Valerie Delpech, David Dunn, Martin Fisher, Sophie Jose, Brian Gazzard, Richard Gilson, Phillip Hay, Mark Gompels, Teresa Hill, Margaret Johnson, Stephen Kegg, Clifford Leen, Mark Nelson, Chloe Orkin, Adrian Palfreeman, Andrew Phillips, Deenan Pillay, Frank Post, Caroline Sabin (PI), Memory Sachikonye, Achim Schwenk, John Walsh.

Central Co-ordination: UCL Research Department of Infection \& Population Health, Royal Free Campus, London (Teresa Hill, Sophie Jose, Susie Huntington, Andrew Phillips, Caroline Sabin, Alicia Thornton); Medical Research Council Clinical Trials Unit (MRC CTU), London (David Dunn, Adam Glabay).

Participating Centres: Barts and The London NHS Trust, London (Chloe Orkin, Nigel Garrett, Janet Lynch, James Hand, Carl de Souza); Brighton and Sussex University Hospitals NHS Trust (Martin Fisher, Nicky Perry, Stuart Tilbury, Elaney Youssef, Duncan Churchill); Chelsea and Westminster Hospital NHS Foundation Trust, London (Brian Gazzard, Mark Nelson, Matthew Waxman, David Asboe, Sundhiya Mandalia); Public Health England (PHE), London (Valerie Delpech); Homerton University Hospital NHS Trust, London (Jane Anderson, Sajid Munshi, Damilola Awosika); King's College Hospital NHS Foundation Trust, London (Frank Post, Hardik Korat, Chris Taylor, Zachary Gleisner, Fowzia Ibrahim, Lucy Campbell); Medical Research Council Clinical Trials Unit (MRC CTU), London (Abdel Babiker, David Dunn, Adam Glabay); Middlesbrough, South Tees Hospitals NHS Foundation Trust, (David Chadwick, Kirsty Baillie); Mortimer Market Centre, University College London Medical School, London (Richard Gilson, Nataliya Brima, lan Williams); North Middlesex University Hospital NHS Trust, London (Jonathan Ainsworth, Achim Schwenk, Sheila Miller, Chris Wood); Royal Free Hampstead NHS Trust/University College London Medical School, London (Margaret Johnson, Mike Youle, Fiona Lampe, Colette Smith, Helen Grabowska, Clinton Chaloner, Sophie Jose, Alicia Thornton, Teresa Hill, Susie Huntington, Andrew Phillips, Caroline Sabin); Imperial College Healthcare NHS Trust, London (John Walsh, Jonathan Weber, Farhan Ramzan, Mark Carder); The Lothian University Hospitals NHS Trust, Edinburgh (Clifford Leen, Alan Wilson); North Bristol NHS Trust (Mark Gompels, Sue Allan); Leicester, University Hospitals of Leicester NHS Trust (Adrian Palfreeman, Anne Moore, Lynn Fox, Josef Bojanowski); Woolwich, South London Healthcare NHS Trust (Stephen Kegg, Paul Main, Dr. Mitchell, Dr. Hunter), UK Community Advisory Board (Memory Sachikonye); St. George's Healthcare NHS Trust (Phillip Hay, Mandip Dhillon). NSHPC: We gratefully acknowledge the contribution of the midwives, obstetricians, genitourinary physicians, paediatricians, clinical nurse specialists and all other colleagues who report to the NSHPC through the British Paediatric Surveillance Unit of the Royal College of Paediatrics and Child Health, and the obstetric reporting scheme run under the auspices of the Royal College of Obstetricians and Gynaecologists. We thank Icina Shakes for administrative support. We also acknowledge the invaluable contribution of Janet Masters, NSHPC data manager and coordinator for many years until her death in 2012. 


\section{Sources of funding}

The UK Collaborative HIV Cohort (UK CHIC) study is funded by the Medical Research Council (MRC), UK (grants G00001999 and G0600337). The Nationa Study of HIV in Pregnancy and Childhood (NSHPC) receives core funding from PHE (previously the Health Protection Agency) (grant number GHP/ 003/013/003). Data are collated at the UCL Institute of Child Health which receives a proportion of funding from the Department of Health's National Institute for Health Research Biomedical Research Centres funding Scheme. S Huntington has a UCL Studentship, funded by the MRC, for postgraduate work and C Thorne held a Wellcome Trust Research Career Development Fellowship. The views expressed in this manuscript are those of the researchers and not necessarily those of the funders.

\section{Author details}

Centre for Paediatric Epidemiology and Biostatistics, UCL Institute of Child Health, 30 Guilford Street, London WC1N 1EH, UK. ${ }^{2}$ HIV Epidemiology and Biostatistics Group, UCL Research Department of Infection and Population Health, Royal Free Campus, Rowland Hill Street, London NW3 2PF, UK. ${ }^{3}$ Homerton University Hospital NHS Foundation Trust, Homerton Row, London E9 6SR, UK. ${ }^{4}$ Faculty of Medicine, University of Southampton, Building 85, Life Sciences Building, Highfield Campus, University Rd, Southampton SO17 1BJ, UK. ${ }^{5}$ Faculty of Medicine, Imperial College, London, UK. ${ }^{6}$ Public Health England (PHE) Cfl, 61 Colindale Avenue, London NW9 $5 \mathrm{HT}, \mathrm{UK}$

Received: 5 November 2013 Accepted: 26 February 2014 Published: 4 March 2014

\section{References}

1. Hawkins D, Blott M, Clayden P, de Ruiter A, Foster G, Gilling-Smith C, Gosrani B, Lyall H, Mercey D, Newell ML, O'Shea S, Smith R, Sunderland J, Wood C, Taylor G: Guidelines for the management of HIV infection in pregnant women and the prevention of mother-to-child transmission of HIV. HIV Med 2005, 6:107-148.

2. de Ruiter A, Taylor G, Palfreeman A, Clayden P, Dhar J, Gandhi K, Gilleece Y, Harding K, Hay P, Kennedy J, Low-Beer N, Lyall H, Tookey P, Welch S, Wilkins E: British HIV association and children's HIV association guidelines for the management of HIV infection in pregnant women 2012. HIV Med 2012. 13:87-157.

3. Williams I, Churchill D, Anderson J, Boffito M, Bower M, Cairns G, Cwynarski K, Edwards S, Fidler S, Fisher M, Freedman A, Geretti AM, Gilleece Y, Horne R, Johnson M, Khoo S, Leen C, Marshall N, Nelson M, Orkin C, Paton N, Phillips A, Post F, Pozniak A, Sabin C, Trevelion R, Ustianowski A, Walsh J, Waters L, Wilkins E, et al: British HIV association guidelines for the treatment of HIV-1 positive adults with antiretroviral therapy 2012. (updated November 2013). HIV Med 2014, 15:1-85.

4. Arrive E, Newell ML, Ekouevi DK, Chaix ML, Thiebaut R, Masquelier B, Leroy V, Perre PV, Rouzioux C, Dabis F: Prevalence of resistance to nevirapine in mothers and children after single-dose exposure to prevent vertical transmission of HIV-1: a meta-analysis. Int J Epidemiol 2007, 36:1009-1021.

5. Lockman S, Shapiro RL, Smeaton LM, Wester C, Thior I, Stevens L, Chand F, Makhema J, Moffat C, Asmelash A, Ndase P, Arimi P, van Widenfelt E, Mazhani L, Novitsky V, Lagakos S, Essex M: Response to antiretroviral therapy after a single, peripartum dose of nevirapine. N Engl J Med 2007, 356:135-147.

6. Ekpini RA, Nkengasong JN, Sibailly T, Maurice C, Adje C, Monga BB, Roels TH, Greenberg AE, Wiktor SZ: Changes in plasma HIV-1-RNA viral load and CD4 cell counts, and lack of zidovudine resistance among pregnant women receiving short-course zidovudine. AIDS 2002, 16:625-630.

7. Read P, Costelloe S, Mullen J, O'Shea S, Lyons F, Hay P, Welch J, Larbalestier N, Taylor G, de Ruiter A: New mutations associated with resistance not detected following zidovudine monotherapy in pregnancy when used in accordance with British HIV association guidelines. HIV Med 2008, 9:448-451.

8. Larbalestier N, Mullen J, O'Shea S, Cottam F, Sabin CA, Chrystie IL, Welch J, Zuckerman M, Hay P, Rice P, Taylor GP, de Ruiter A: Drug resistance is uncommon in pregnant women with low viral loads taking zidovudine monotherapy to prevent perinatal HIV transmission. AIDS 2003, 17:2665-2667.

9. Bardeguez AD, Shapiro DE, Mofenson LM, Coombs R, Frenkel LM, Fowler MG, Huang S, Sperling RS, Cunningham B, Gandia J, Maupin R, Zorrilla CD, Jones T, O'Sullivan MJ: Effect of cessation of zidovudine prophylaxis to reduce vertical transmission on maternal HIV disease progression and survival. J Acquir Immune Defic Syndr 2003, 32:170-181.
10. Fowler MG, Mofenson L, McConnell M: The interface of perinatal HIV prevention, antiretroviral drug resistance, and antiretroviral treatment: what do we really know? J Acquir Immune Defic Syndr 2003, 34:308-311.

11. Nolan M, Fowler MG, Mofenson LM: Antiretroviral prophylaxis of perinatal HIV-1 transmission and the potential impact of antiretroviral resistance. J Acquir Immune Defic Syndr 2002, 30:216-229.

12. Welles SL, Pitt J, Colgrove R, McIntosh K, Chung PH, Colson A, Lockman S, Fowler MG, Hanson C, Landesman S, Moye J, Rich KC, Zorrilla C, Japour AJ: HIV-1 genotypic zidovudine drug resistance and the risk of maternal infant transmission in the women and infants transmission study. The women and infants transmission study group. AIDS 2000, 14:263-271.

13. Kully C, Yerly S, Erb P, Kind C, Krautheim A, Perrin L, Rudin C: Codon 215 mutations in human immunodeficiency virus-infected pregnant women. Swiss collaborative 'HIV and pregnancy' study. J Infect Dis 1999, 179:705-708.

14. World Health Organization: Consolidated guidelines on the use of antiretroviral drugs for treating and preventing HIV infection: recommendations for a public health approach. 2013. [http://www.who. int/hiv/pub/guidelines/arv2013/en/

15. Bailey H, Townsend CL, Semenenko I, Malyuta R, Cortina-Borja M, Thorne C: Impact of expanded access to combination antiretroviral therapy in pregnancy: results from a cohort study in Ukraine. Bull World Health Organ 2013, 91:491-500.

16. NSHPC: The NSHPC website. 2014. [www.nshpc.ucl.ac.uk]

17. UK CHIC: The UK CHIC website. 2014. [www.ukchic.org.uk]

18. Huntington SE, Bansi L, Thorne C, Anderson J, Newell ML, Taylor GP, Pillay D, Hill T, Tookey P, Sabin CA: Using two on-going HIV studies to obtain clinical data from before, during and after pregnancy for HIV-positive women. BMC Med Res Methodol 2012, 12:110.

19. Sperling RS, Shapiro DE, McSherry GD, Britto P, Cunningham BE, Culnane M, Coombs RW, Scott G, Van Dyke RB, Shearer WT, Jimenez E, Diaz C, Harrison DD, Delfraissy JF: Safety of the maternal-infant zidovudine regimen utilized in the Pediatric AIDS Clinical Trial Group 076 Study. AIDS 1998, 12:1805-1813

20. Watts DH, Lambert J, Stiehm ER, Harris DR, Bethel J, Mofenson L, Meyer WA III, Mathieson B, Fowler MG, Nemo G: Progression of HIV disease among women following delivery. J Acquir Immune Defic Syndr 2003, 33:585-593.

21. Roxby AC, Drake AL, Ongecha-Owuor F, Kiarie JN, Richardson B, Matemo DN, Overbaugh J, Emery S, John-Stewart GC, Wald A, Farquhar C: Effects of valacyclovir on markers of disease progression in postpartum women co-infected with HIV-1 and herpes simplex virus-2. PLoS One 2012, 7:e38622.

22. Shapiro RL, Hughes MD, Ogwu A, Kitch D, Lockman S, Moffat C, Makhema J, Moyo S, Thior I, Mclntosh K, Van WE, Leidner J, Powis K, Asmelash A, Tumbare E, Zwerski S, Sharma U, Handelsman E, Mburu K, Jayeoba O, Moko E, Souda S, Lubega E, Akhtar M, Wester C, Tuomola R, Snowden W, Martinez-Tristani M, Mazhani L, Essex M: Antiretroviral regimens in pregnancy and breast-feeding in Botswana. N Engl J Med 2010, 362:2282-2294.

doi:10.1186/1471-2334-14-127

Cite this article as: Huntington et al:: Response to antiretroviral therapy (ART): comparing women with previous use of zidovudine monotherapy (ZDVm) in pregnancy with ART naïve women. BMC Infectious Diseases 2014 14:127.

\section{Submit your next manuscript to BioMed Central and take full advantage of:}

- Convenient online submission

- Thorough peer review

- No space constraints or color figure charges

- Immediate publication on acceptance

- Inclusion in PubMed, CAS, Scopus and Google Scholar

- Research which is freely available for redistribution 